\title{
Stress Relaxation in SSC 50MMM Dipole Coils
}

\author{
D. Rogers and F. Markley \\ Fermi National Accelerator Laboratory \\ P.O. Box 500, Batavia, Illinois 60510
}

\section{DISCLAIMER}

\begin{abstract}
This report was prepared as an account of work sponsored by an agency of the United States Government. Neither the United States Government nor any agency thereof, nor any of their employees, makes any warranty, express or implied, or assumes any legal liability or responsibility for the accuracy, completeness, or usefulness of any information, apparatus, product, or process disclosed, or represents that its use would not infringe privately owned rights. Reference herein to any specific commercial product, process, or service by trade name, trademark, manufacturer, or otherwise does not necessarily constitute or imply its endorsement, recommanufacturer, or otherwise doe United States Government or any agency thereof. The views and opinions of authors expressed herein do not necessarily state or reflect those of the United States Government or any agency thereof.
\end{abstract}

April 1992

Presented at the Fourth Annual IISSC Conference, New Orleans, LA, March 4-6, 1992.

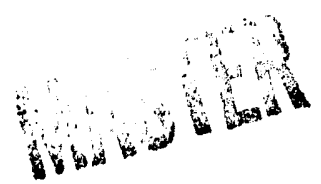




\section{Disclaimer}

This report was prepared as an account of work sponsored by an agency of the United States Government. Neither the United States Government nor any agency thereof, nor any of their employees, makes any warranty, express or implied, or assumes any legal liability or responsibility for the accuracy, completeness, or usefulness of any information, apparatus, product, or process disclosed, or represents that its use would not infringe privately owned rights. Reference herein to any specific commercial product, process, or service by trade name, trademark, manufacturer, or otherwise, does not necessarily constitute or imply its endorsement, recommendation, or favoring by the United States Government or any agency thereof. The views and opinions of authors expressed herein do not necessarily state or reflect those of the United States Government or any agency thereof. 


\title{
STRESS RELAXATION IN SSC 50MM DIPOLE COIIS
}

\author{
Daniel Rogers and Finley Markley \\ Fermi National Accelerator Laboratory* \\ Box 500 \\ Batavia, IL 60510
}

\begin{abstract}
We are measuring the stress relaxation of SSC $50 \mathrm{~mm}$ outer coils with the goal of predicting how much of the coil prestress will be lost while the coils are warehoused between manufacture and cooldown. We manufacture 3 inch $(76.2 \mathrm{~mm})$ long segments of coil with the same materials and techniques that have been used for prototype coils. We are running four simultaneous tests in an attempt to separate the contributions of the different coil materials. Test one is a completely insulated coil section where the insulation is the all polyimide system being tested at Brookhaven; tesi two is a wire stack insulated only with the normal Kapton overwrap; test three is a stack of bare cable; and test four is a completely insulated normal coil section. All, except for the bare cable, include the ground insulation. The insulated coil sections are carefully dried before loading and testing in order to eliminate stress changes due to varying moisture content. The temperature dependence of the stress relaxation is being studied separately. Three companion papers presented at this conference will be: 1) "Temperature dependence of the viscoelastic properties of SSC coil insulation" 2) "Measurement of the elastic modulus of Kapton perpendicular to the plane of the Eilm at room and cryogenic temperatures" 3) "Theoretical methods for creep and stress relaxation studies of SSC coil."
\end{abstract}

\section{INTRODUCTION}

The purpose of these coil studies is to analyze the mechanical property of stress relaxation with respect to time and temperature. This is an extremely important property of superconducting magnet coils.1 Such studies are necessary because the magnets may fail at great cost if this critical physical property is not fully understood, accounted for, and utilized. Magnet designs have been improved immensely in recent years, resulting in much more

\footnotetext{
- Operated by the Universities Research Association. Inc.. for the U.S. Department of Energy.
} 
reliable magnets. It is hoped that through additional design modifications, the rate of magnet failure will be reduced even further. Although this is the first stress relaxation testing on $50 \mathrm{~mm}$ coils, this is a continuation of previous studies conducted at this facility, with additional improvements in testing methods and fixtures.

Stress relaxation studies involve the compressing of a magnet coil to a predetermined size and monitoring the changing amount of force (with respect to time) required to maintain this coil size. In other words, the strain is held constant while the amount of stress varies. This is not the same phenomena as creep, where the stress is constant and the strain varies. This particular method of stress relaxation testing was developed to simulate the conditions of an actual production magnet coil which has been compressed and collared through the normal manufacturing process. It is important for such coils to remain in their highly compressed state during long periods of processing, shipping, and storage, so that on final cool down the coil will not move causing a quench.

\section{PROBLEMS WTTH COIL TESTING}

\section{Coil Geometry}

Due to variation in coil strand size and insulation thickness, it is not possible to accurately predict either coil size or stiffness. As a result, we cannot very well predict coil stress when a particular coil segment is compressed in a fixture made to represent an actual collar. These problems cannot be eliminated, since such variations will always exist in these coils.

\section{Environment}

Other possible sources of inconsistency are temperature and humidity. Attempts are made to control humidity by placing desiccant inside of the acrylic boxes which contain the test fixtures. In addition, many efforts are made to maintain a constant temperature level by thermally isolating the test fixtures and incorporating electric heaters with PID temperature controllers. Unfortunately, temperature controllers are not $100 \%$ accurate and do allow a slight amount of temperature deviation. The time/temperature effects on coil stress are not predictable, as the theoretical time/temperature shift factor $(k)$ for these coils has not yet been determined. Consequently, to avoid further complications, it was decided not to introduce any intentional temperature changes. The set point used for all of this testing is $100^{\circ} \mathrm{F},(311 \mathrm{~K})$.

\section{Fabrication of Coil Samples}

In order to study magnet coils, a source of these coils is necessary. It would be extremely costly to do destructive testing of complete full size coils. Therefore, sample coil segments were manufactured specifically for this series of tests. This also allows certain variations in the coil samples which would not otherwise be available. We believe that straight stacks, (ten stacks) manufactured by flipping alternate cables, do not adequately model real coils. It cannot be said that these samples are manufactured in every detail absolutely identical to the real coils. They are, however, manufactured in such a way as to simulate actual production techniques, and are believed to be (for the purposes of these tests) reasonably representative of actual production coils. 
In addition to studying "regular" coils, it is also of interest to try some coil variations for comparison. Consequently, four differer.t types of coil samples are fabricated. First there is the "regular" Kapton/epoxy/ fiberglass coil. (Kapton is a "trade name" for a polyimide, which is a thermoplastic used for wire insulation). Next, a second coil ("no fiberglass") is made, which is identical to the fi:st, except without the epoxy/fiberglass. Another coil ("bare wire") is made from identical materials, except without either the epoxy/fiberglass or the Kapton. The fourth variation is to incorporate the experimental DuPont Kapton CI system. This fourth type of coil ("Special Kapton" - also referred to as "Kapton only", "all Kapton", or high temperature Kapton") requires special fabrication techniques. This "special Kapton" coil was made as per procedures obtained from Brookhaven National Laboratory, where tests are also being conducted on this experimental polyimide insulation system.

\section{Experimental Setup}

A drawing of a coil stress relaxation test fixture is shown in figure 1. Four of these fixtures were made for these studies. Each was designed for one of the four coil sample types. Each fixture was intended to apply force to the sample in order to achieve coil stress levels which fall within the range of those of actual production coils. The fixtures for "bare wire" and "no fiberglass" coil samples obviously need smaller cavity spaces than the "regular" coil fixture in order to achieve adequate coil compression. Theoretically, "regular" and "special Kapton" coils should be dimensionally identical. However, the actual "special Kapton" coil sample is smaller than "regular" coil samples. Therefore, shims are inserted in the "special Kapton" fixture. In spite of designing fixtures for specific coil sizes, coil sizes may vary and it is sometimes necessary to insert shim stock in with the coil samples to achieve adequate loading.

Each test is conducted with the fixture contained in an acrylic box intended for environmental control. Silica gel desiccant is placed inside the box and the box is sealed with a gasket in an attempt to eliminate bumidity. Fixture temperature is regulated directly by a temperature controller connected to three cartridge heaters installed in the fixture. A load cell installed in the fixture converts force to voltage, which is monitored

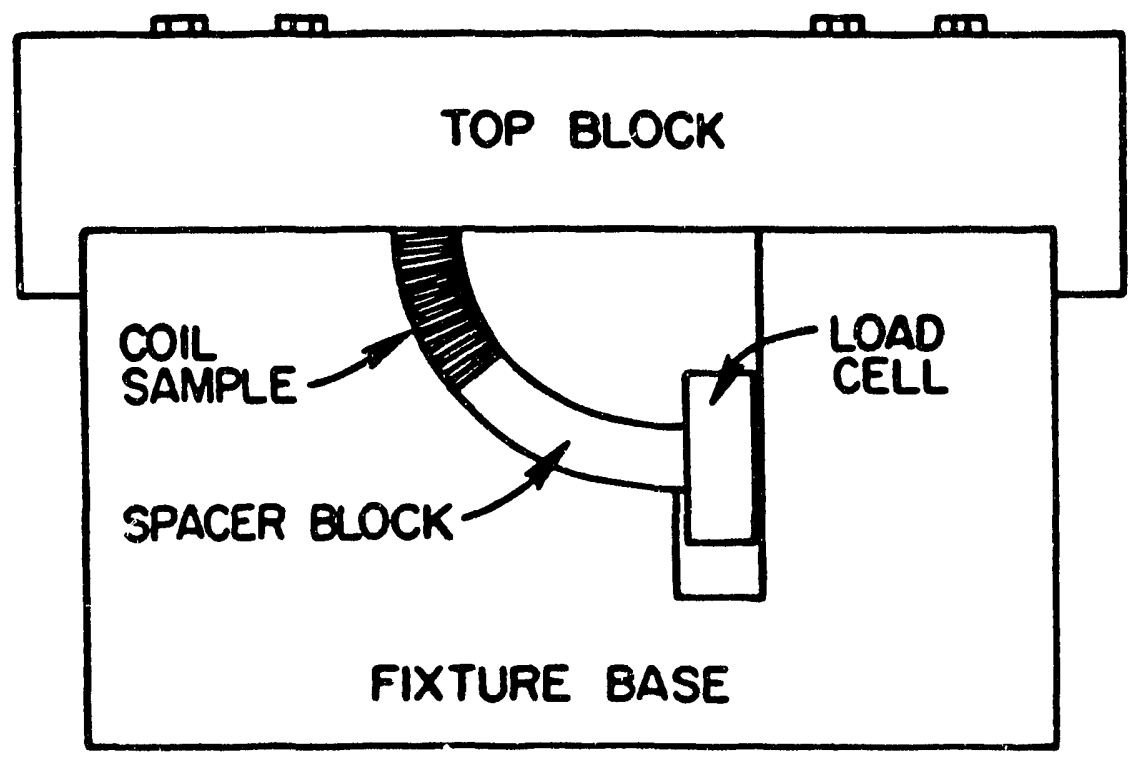

Figure 1. SSC 50mm Dipole Coil Stress Relaxation Test Fixture 
with a voltmeter. The load cell input voltage is supplied by an HP6186c constant current power source.

\section{DATA ACQUISITION AND CONVERSION}

Data is acquired using an IBM PC (with Labtech Notebook) to control an HP75000 card cage/multimeter. The multimeter monitors load cell inputs and outputs and relays data to be stored in data files in the computers hard drive. Because mechanical properties are influenced by temperature, fixture temperatures are also monitored. The data files generated are converted to load and temperature data. The load cell calibration number (C) and output voltage at zero load $\left(\mathrm{V}_{\mathrm{zl}}\right)$ are used to convert load cell voltages to force in lbs. Effects of possible power supply voltage fluctuations are compensated for by incorporating the load cell input voltage $\left(V_{\text {in }}\right)$, as well as the output $\left(V_{\text {out }}\right)$, in this data conversion.

$$
\text { Load (lbs) }=\frac{V_{\text {out }} \cdot V_{\text {zl }}}{V_{\text {in }}} * C
$$

\section{TAST PROCEDURE}

First, the proper positioning of the coil sample, insulating ground wrap, and shim is verified. Then the fixture top is placed in position and bolts are threaded into the fixture. Alignment of all fixture parts, the load cell, coil, and shim is then verified and the entire setup is visually inspected to insure that everything is intact. The next step is to start the data acquisition program, and note the time, for future reference. Fixture bolts are torqued while monitoring the load cell output to avoid overloading the load cell. When the fixture is completely closed the coil is checked to insure that it is properly seated. The fixture applies a force from 8000 to $16000 \mathrm{lbs}$. $(35-71 \mathrm{kN})$ to the coil section. Applying sufficient torque to the bolts to close the fixture is difficult. Therefore, the entire setup is again visually inspected to see that no damage has occurred. Finally, desiccant is placed in the acrylic box and the box is closed and sealed.

Ideally, these procedures are performed and tests are successfully started on the first try. However, it is sometimes necessary to adjust shim sizes, repair damage, and repeat other procedures. It is also sometimes necessary to delay tests to allow coils to relax after unsuccessfully attempting to start a test.

\section{RESULTING DATA AND ANALYSIS}

Figure 2 illustrates the relationship between load and time for each test. This data is assumed to be representative of the relationship between stress and time, since stress is force per area, and the area is assumed to be a constant 1.38 square inches $(8.90$ square $\mathrm{cm})$. It is conceivable that projected estimates of long term stress decay can be extrapolated directly from such data. Conventional stress relaxation theory is used in analyzing this data. One method of analysis utilized is to try fitting a curve to the data. The result of curve fitting is an equation which theoretically represents the data, thus allowing more accurate long term stress loss estimation. An equation of this form can represent load or stress. $L_{0}$ is the load at time $t=0,\left(L_{0}-L_{1}\right)$ is the 


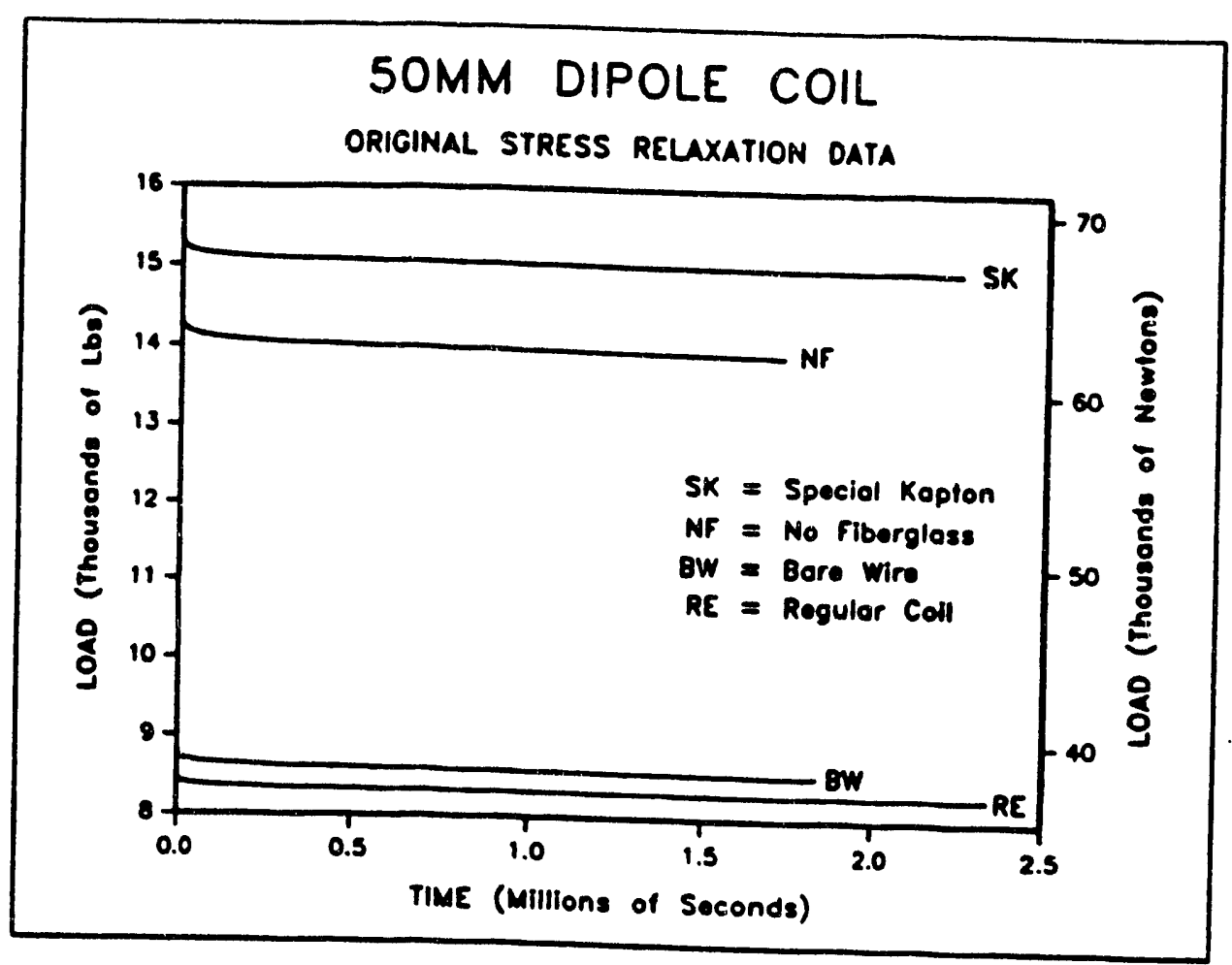

Figure 2. Original Stress Relaxation Data

load at time $t=1, t$ is the time value, $n$ is a constant, and $L$ is the corresponding load value.

$$
L=L_{\emptyset}-L_{1}(t)^{n}
$$

Direct comparison of the raw data from each of the different tests is complicated by variations in starting load $\left(\mathrm{L}_{\mathrm{g}}\right)$ values. Simply adjusting the scales to compare data is inappropriate. It is advantageous to modify the data by dividing through each dataset by its $L_{\varnothing}$ value, thus normalizing all the datasets to start at the value one. The $L \emptyset$ values are first taken as the highest load value in each data file $\left(\mathrm{L}_{\emptyset}=\mathrm{L}_{\mathrm{g}}\right)$. The actual initial loads are probably higher, but are undetected because the loads change very quickly at the start of a test. Ideally, at the start of each test, the load would be applied instantaneously, and the $L_{\emptyset}$ value would be known. However the load is not applied instantaneously and $\mathrm{L}_{\varnothing}$ must be estimated. Therefore, estimated $\mathrm{L}_{\mathrm{s}}$ values are adjusted slightly (within .2\%) to bring the normalized data curves together near the beginning. The resulting curves are shown for comparison in figure 3.

For a different perspective, the beginnings of the tests are examined by again adjusting the initial load values, but this time normalizing the curves to match at time $(T)=300000$ seconds. This arbitrary time value was chosen because it is relatively short term, (between 3 and 4 days), and allows for clear comparisons of the early portion of the tests, but is still long enough to be past uncertainties in starting times due to non-instantaneous load application. The figure 4 data emphasizes the dissimilarity in the initial shape of the curves and figure 3 shows overall differences in relaxation. These differences are probably due to coil variations for the most part and may indicate little more than that the copper dominates the total coil relaxation. 


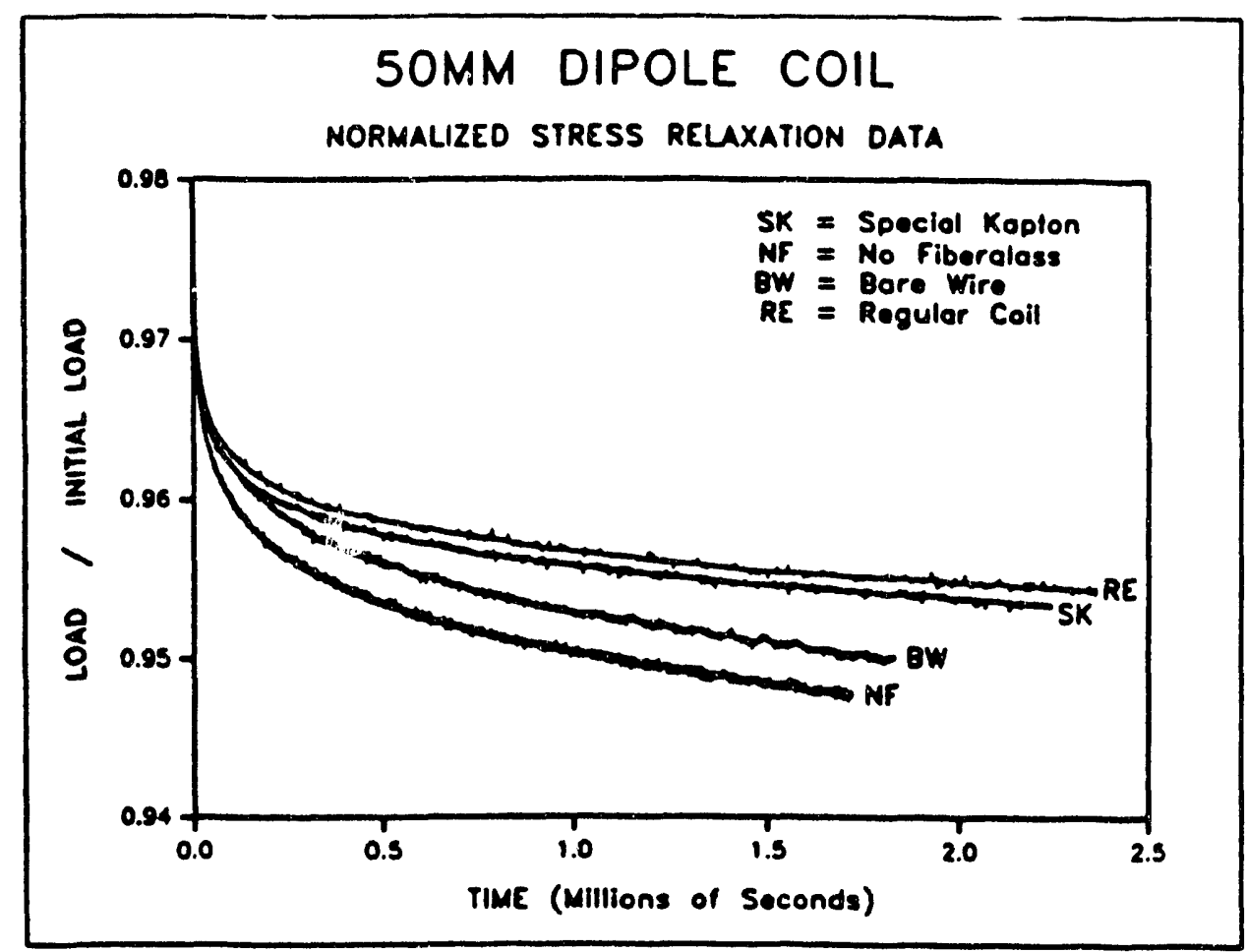

Figure 3 . Stress Relaxation Data normalized to match near the beginning

\section{DATA INTERPRETATION}

The expected order of initial relaxation rate, from highest to lowest, is RE, NF, and BW; (SK is unknown). The apparent relationship between SK and RE may indicate that the absence of the fiberglass/epoxy does not greatly alter the initial relaxation rate, which is not unreasonable to expect. However, the close grouping of NF and BW is surprising. Assuming that the polyimide is the material that does the most relaxing, it is reasonable to expect that NF would initially relax at a higher rate than BW.2

It is not yet known if this data is repeatable. It is possible that, through repetition, it may become obvious that this individual comparison is not a good representation of the relative properties of this coil type. On the other hand, if this did prove to be a good coil model, it may be that the properties were altered in an unpredirtable manner. One possible explanation for a high rate of relaxation for the bare wire coil is that the affect of the change in contact area (between the wire strands and insulation) is overshadowing the stress relaxation. When a coil is compressed, the stress is equal to the yield point of copper ${ }^{3}$ and the shape of the wire strands and insulation changes. Perhaps the insulating components and wire strands are compressed in such a manner as to increase the contact area, thusly reducing the stress. This variation cannot be controlled because of variation in wire strand diameter and insulation thickness. As a result, a great deal of test data variation occurs.

The normalization implies a linear relationship between stress and strain at any time, which is probably not true at stresses equal to the rield stress. Therefore, a much better comparison would be to start all measurement at the same stress value. But this is not possible, because true internal stresses are unknown. Even starting at the same overall stress is experimentally difficult. 


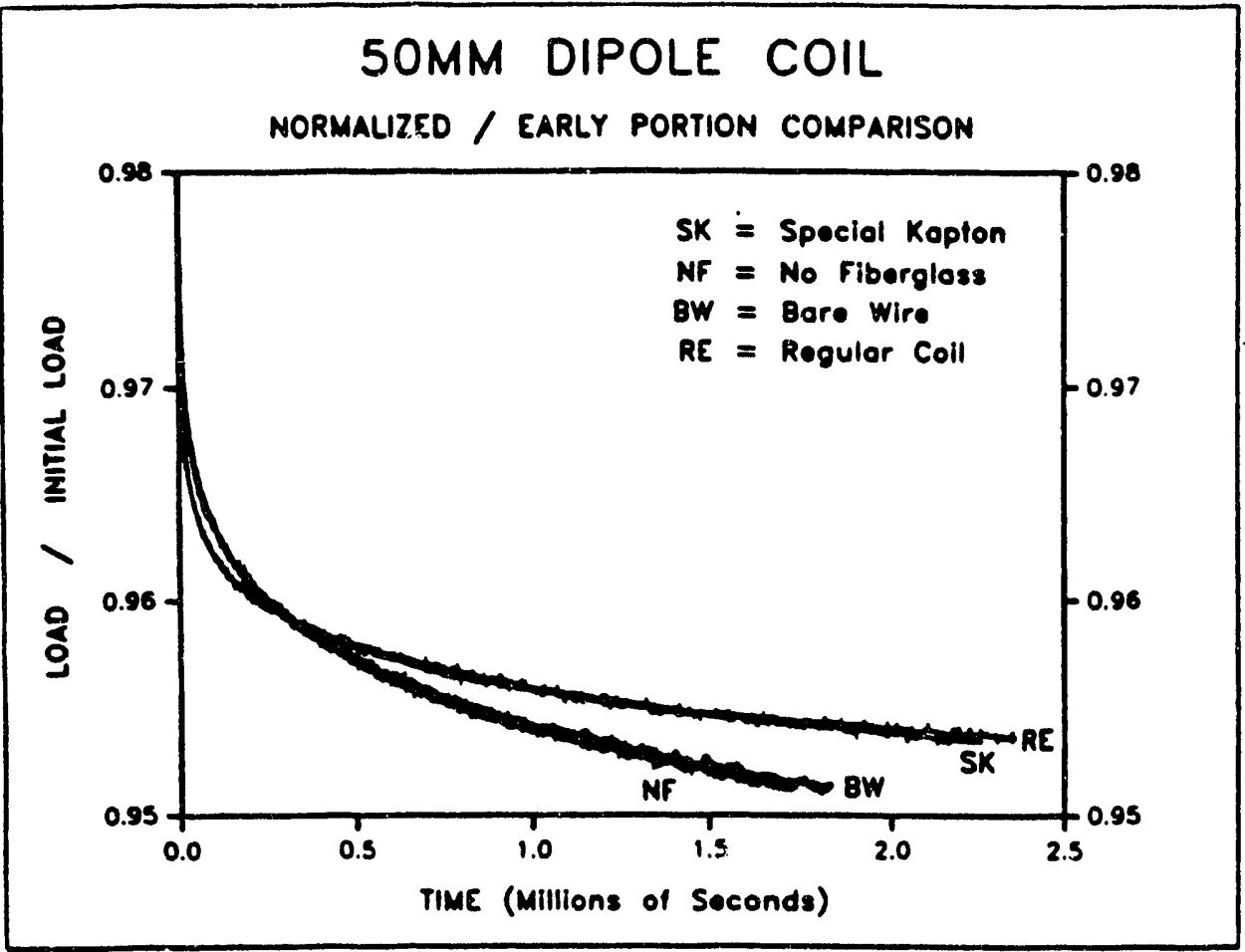

Figure 4. Data normalized for early portion comparison

\section{CONCLUSTON}

The actual areas of contact between cable strands in the coil (i.e. the true area of support) is the most important element in determining stress relaxation. Stress relaxation in the bare wire appears to dominate the total coil stress relaxation. It is very difficult to extrapolate long term stress loss, but we are currently preparing to make such an estimate.

\section{REFERENCES}

1. Carson, J.A. and F.W. Markley, "Mechanical Properties of

Superconducting Coils," IEEE Transactions on Magnetics, Vol.

Mag. 21 \#2, March 1985, pp. 85.

2. Markley, F.W., and J.S. Kerby, "Investigation of the Mechanical

Properties of Superconducting Coils," Super Collider 2, Vol. 2, Plenum Press, New York, 1990, pp. 753-763.

3. Markley, F.W., et. al., "Stress Relaxation in SSC Collared Coils and their Component Materials," Super_Collider 3, Vol. 3, Plenum Press, New York, 1991, pp. 155-163. 

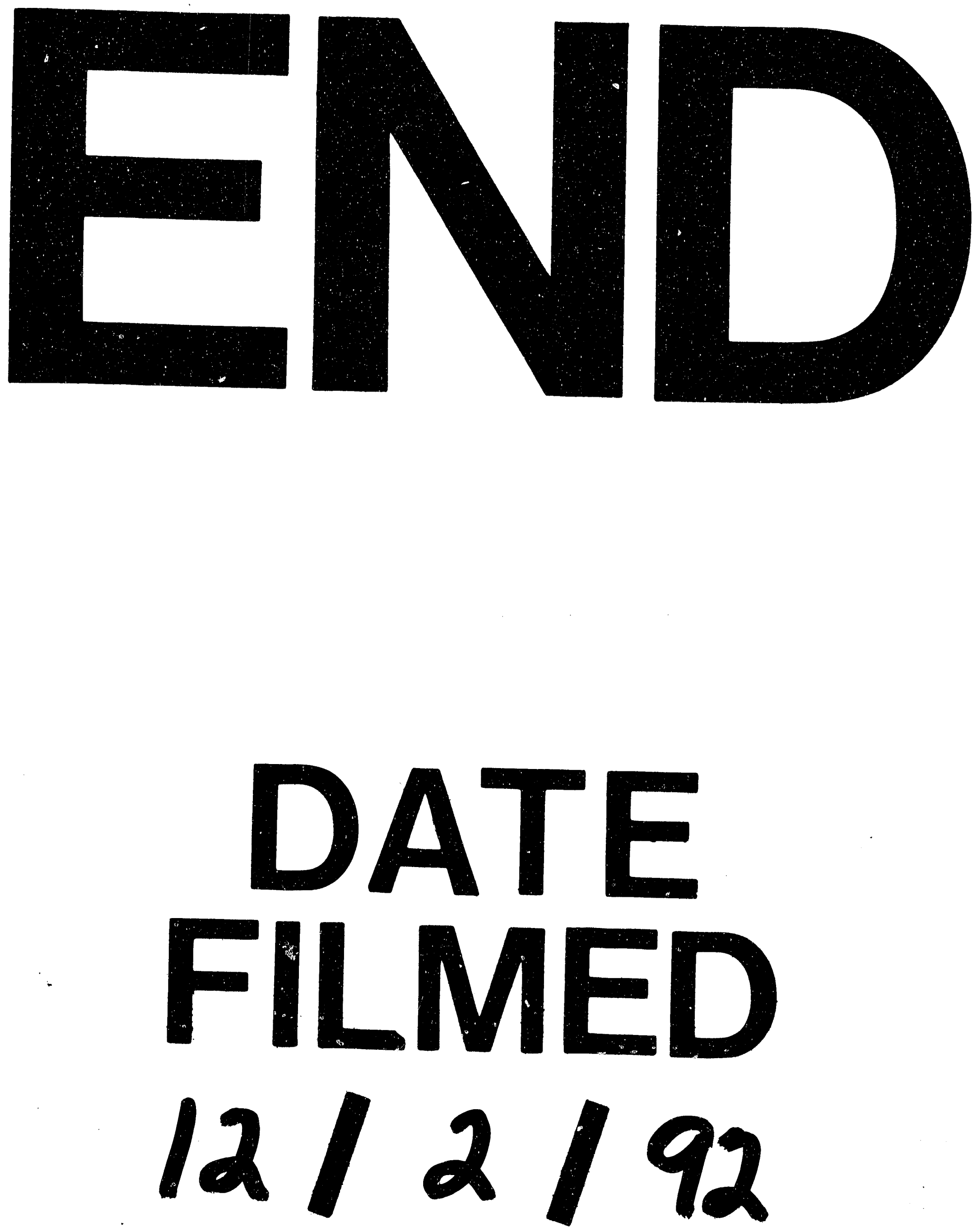
